\title{
Understanding neuronal connectivity through the post-transcriptional toolkit
}

\author{
Carlos M. Loya, ${ }^{2}$ David Van Vactor, ${ }^{1}$ and Tudor A. Fulga \\ Department of Cell Biology, Harvard Medical School, Boston, Massachusetts 02115, USA
}

\begin{abstract}
Post-transcriptional regulatory mechanisms have emerged as a critical component underlying the diversification and spatiotemporal control of the proteome during the establishment of precise neuronal connectivity. These mechanisms have been shown to be important for virtually all stages of assembling a neural network, from neurite guidance, branching, and growth to synapse morphogenesis and function. From the moment a gene is transcribed, it undergoes a series of post-transcriptional regulatory modifications in the nucleus and cytoplasm until its final deployment as a functional protein. Initially, a message is subjected to extensive structural regulation through alternative splicing, which is capable of greatly expanding the protein repertoire by generating, in some cases, thousands of functionally distinct isoforms from a single gene locus. Then, RNA packaging into neuronal transport granules and recognition by RNA-binding proteins and/or microRNAs is capable of restricting protein synthesis to selective locations and under specific input conditions. This ability of the posttranscriptional apparatus to expand the informational content of a cell and control the deployment of proteins in both spatial and temporal dimensions is a feature well adapted for the extreme morphological properties of neural cells. In this review, we describe recent advances in understanding how post-transcriptional regulatory mechanisms refine the proteomic complexity required for the assembly of intricate and specific neural networks.
\end{abstract}

The formation of accurate neuronal connectivity during nervous system development is essential for higher-order cognitive and motor behaviors. Neurons face the monumental task of guiding axons and dendrites to their target locations and then triggering proper and specific synapse formation. Best illustrating this challenge is the human brain, composed of $10^{12}$ neurons that develop $\sim 10^{15}$ connections (Williams and Herrup 1988). For this daunting level of complexity to arise, Roger Sperry proposed in

[Keywords: Local translation; post-transcriptional regulation; alternative splicing; axon and synapse development; microRNA; neuronal connectivity] Corresponding authors.

${ }^{1}$ E-MAIL Davie_vanvactor@hms.harvard.edu; FAX (617) 432-2808.

${ }^{2}$ E-MAIL Carlos_Loya@hms.harvard.edu; FAX (617) 432-2808.

Article is online at http://www.genesdev.org/cgi/doi/10.1101/gad.1907710. the mid-20th century (Sperry 1963) that neural projections must possess chemical "tags" to specifically guide neurites (i.e., axons or dendrites) to their final destinations and promote synapse differentiation, morphogenesis, and function. This suggested the requirement for possibly billions of chemically distinct neuronal branches and synaptic sites. However, given that our genome is composed of only $3 \times 10^{4}$ genes, this implies that amplification of genomic information must be responsible for this staggering intricacy. Interestingly, studies of axonal guidance and synaptogenesis have revealed that a shared and relatively small number of signaling factors and pathways such as Netrins, Ephrins, Wnts, and BMPs are involved in this developmental continuum of establishing neuronal connectivity (Karlstrom et al. 1997; Garbe and Bashaw 2004; Keshishian and Kim 2004; Speese and Budnik 2007; Manitt et al. 2009). Thus, one can argue that, from a molecular perspective, connectivity is governed by a central toolkit that is limited in size. This toolkit is deployed through cell type-specific transcriptional codes and combinations of signaling factors. While graded and combinatorial expression of multiple cues or receptors can increase the capabilities of this limited repertoire (Flanagan and Vanderhaeghen 1998; Flanagan 2006), emerging studies reveal that nature has also expanded the information content in both spatial and temporal dimensions by introducing layers of regulation between the primary transcript and its expression as functional protein.

Proteome diversification through post-transcriptional regulation

Recent studies have shown that precursor mRNA (premRNA) alternative splicing (AS), mRNA transport, and microRNA (miRNA)-mediated translational repression form a fundamental regulatory apparatus used to refine and diversify the proteome during nervous system development (Lipscombe 2005; Bramham et al. 2007; Bushati and Cohen 2007).

AS is a mechanism capable of generating virtually thousands of functionally distinct proteins from a single gene locus. This diversification of the functional protein repertoire has been shown to play a critical role in nearly every stage of neuronal connectivity, from axonal guidance to synapse differentiation and function (Craig and Kang 2007; Li et al.2007; Hattori et al. 2008). 
The elaboration of complex neuronal morphologies requires precise orchestration of protein deployment in different cellular compartments and developmental stages. Given that, in some neurons, the distance between soma and terminal neuritic structures can be on the order of meters, growth cones and synapses have evolved mechanisms to respond rapidly to local stimuli by selectively placing mRNA at sites of action (Fig. 1). This allows translation to occur independently of the cell body at the right place and time. The underlying mechanisms governing this process involve the packaging of mRNA into ribonucleoprotein (RNP) transport granules in the nucleus that are later exported to the cytosol and delivered selectively to distal sites of the neuron in a microtubule-kinesin-dependent fashion (Fig. 1; Kiebler and Bassell 2006). During transport, mRNA translation is reversibly inhibited by RNA-binding proteins (RBPs) and/ or miRNAs through the specific recognition of sequences in the mRNA untranslated regions (UTRs). Both RBP- and miRNA-mediated translational repression have emerged as important post-transcriptional mechanisms able to modulate protein levels with spatial and temporal specificity during the patterning and growth of neuronal connections (Ule and Darnell 2006; Schratt 2009).

In this review, we discuss how AS, RNA transport, and miRNA are used by the nervous system to add functional versatility to a compact collection of molecules to assemble complex neural networks. While the scope of this review is not exhaustive, we highlight a few recent examples for each process to illustrate our current understanding of the underlying mechanisms.

\section{AS}

The majority of eukaryotic genes are composed of multiple coding sequences (exons) separated by noncoding regions (introns). Following transcription, exons of premRNAs are spliced together to form a mature mRNA transcript (Fig. 2A). During nervous system development, pre-mRNA AS dramatically expands proteome diversity by specifically selecting the inclusion or exclusion of exons in a given mRNA (Fig. 2A; Lipscombe 2005; Li et al. 2007); for a general review on splicing, see Nilsen and Graveley (2010). Recent studies using exon-exon junction (Johnson et al. 2003) and whole-genome exon arrays (Clark et al. 2007), or high-throughput sequencing (Wang et al. 2008) show that $\sim 74 \%-94 \%$ of human multiexon genes are alternatively spliced, underscoring the role AS plays in expanding the molecular database of the cell. Moreover, of the transcripts expressed during nervous system development, $28 \%$ demonstrate tissue-specific AS (Johnson et al. 2009).

\section{AS regulates neural patterning and specificity}

A quintessential example of the potential AS has to diversify the molecular identity of a cell and mediate neural wiring comes from studies of the Drosophila Dscam1 (Down Syndrom cell adhesion molecule) locus (Zipursky et al. 2006; Hattori et al. 2008; Schmucker and Chen 2009). Dscam1 AS has the potential to generate 19,008 isoforms with distinct ectodomain structures that exhibit exquisite homophilic binding specificity (Fig. 2B). This diversity is found to mediate homophilic interbranch repulsion and be critical for the organization of the nervous system (Schmucker et al. 2000; Zhan et al. 2004; Hattori et al. 2007). In a recent study, generation of fly mutants through homologous recombination that harbor 12, 24, 576, 1572, and 4752 potential Dscam1 isoforms showed that expression of thousands of Dscam 1 variants are necessary for self-repulsion of sister branches and appropriate neuronal patterning in three distinct neuron classes (Fig. 2C-E; Hattori et al. 2009).

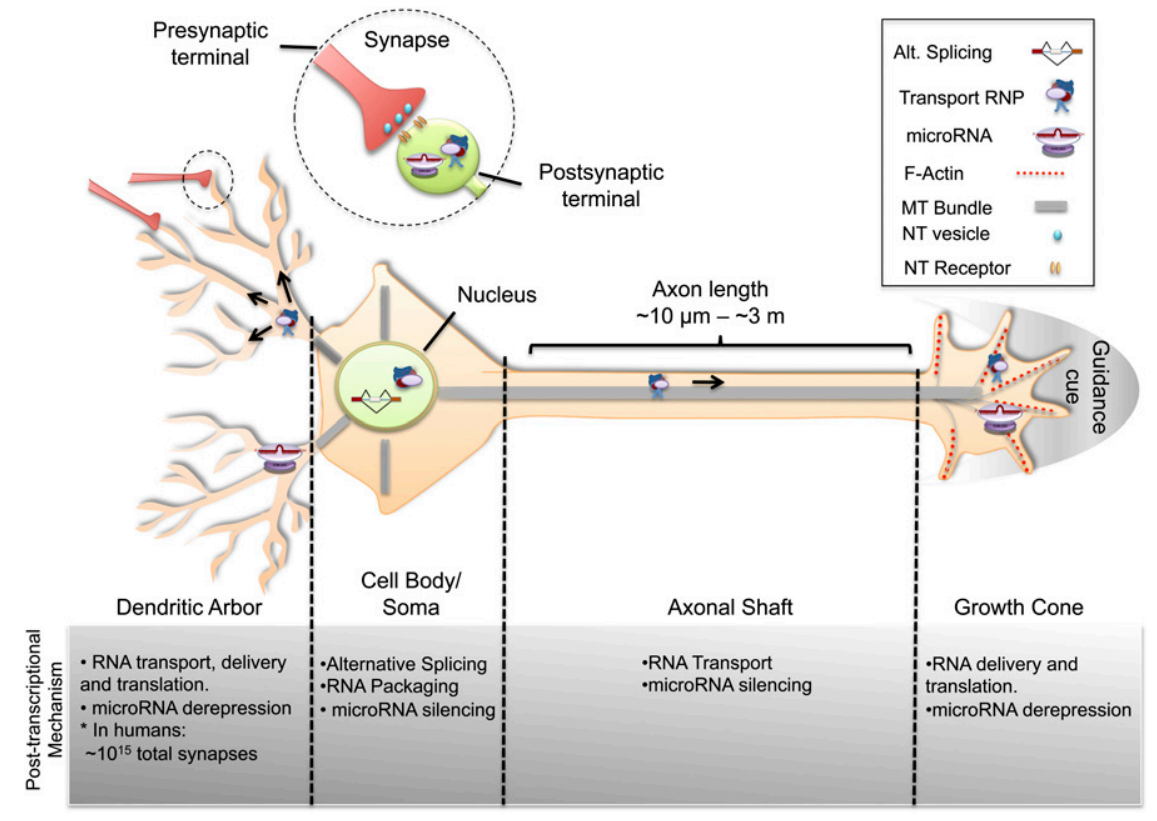

Figure 1. Complexity of neuronal morphology and post-transcriptional regulation. Typical neuron illustrating four gross neuronal anatomical segments: cell body/soma, axonal shaft, dendritic arbor, and growth cone. Inset shows a synapse, with presynaptic and post-synaptic terminals. The post-transcriptional mechanisms highlighted here are AS, RNA transport, and miRNA silencing. AS occurs in the nucleus of the cell body, and is important for generating protein isoforms. Following splicing and mRNA maturation, the transcript can be packaged into transport RNPs, repressed by RBPs and/or miRNAs, delivered to distal sites of the neuron, and locally translated in response to stimulus. Moreover, miRNAs are involved in finely regulating protein levels throughout the cell. 

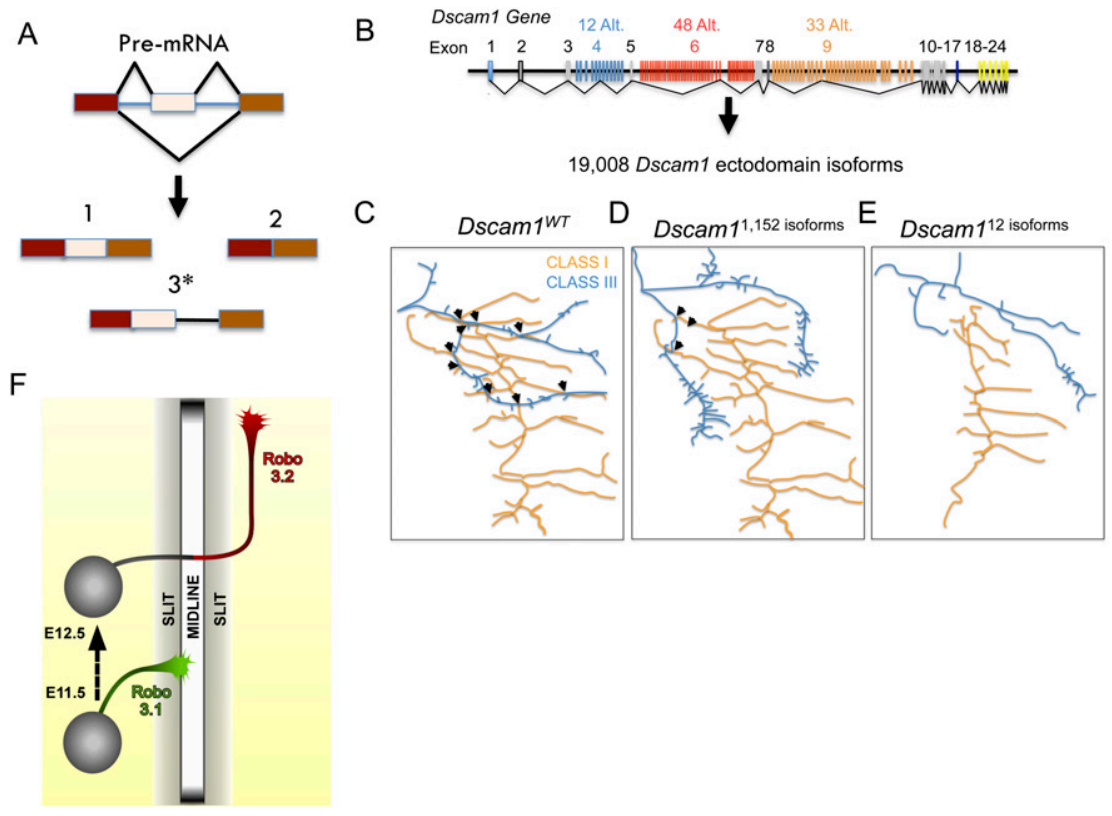
completely avoid each other, indicating that appropriate patterning of dendritic arborization neurons depends on thousands of Dscam 1 isoforms (Hattori et al. 2009). (F) Schematic of a commissural neuron during embryonic development as seen in an open book spinal cord dissection. Axonal shafts represent the differential expression patterns of Robo3 isoforms. In this context, Robo3.1 enables axons to cross the midline, whereas Robo3.2 prevents axons from recrossing (Chen et al. 2008).

Although the role of AS in Dscam function is not conserved in vertebrates, AS of two other adhesion molecules-neurexins (NRX) and neuroligins (NLs)-is important for mammalian pre- and post-synaptic differentiation of excitatory or inhibitory synapses (Craig and Kang 2007). NRXs are presynaptically expressed adhesion proteins with the potential to generate $\sim 1000$ isoforms from two alternative promoters and five alternative splice sites (termed S1-4). Its post-synaptic partner NL (NL1 and NL2) can also undergo extensive AS. NRXs and NLs display selective heterophilic adhesion and distinct capacities to induce excitatory and inhibitory synapse differentiation (Craig and Kang 2007). Overexpression studies in cultured hippocampal neurons have shown that isoforms NL1B and NL1AB specifically bind the $\mathrm{NRX} \beta 4(-)$ variant to selectively induce glutamatergic synapse formation. On the other hand, isoforms NL1A and NL2A bind NRX1 $\alpha 4(-)$ and NRX1 $\beta 4(+)$ to trigger GABAergic synapse differentiation (Boucard et al. 2005; Chih et al. 2006). A comprehensive study of all NL and NRX isoform-specific interactions may reveal further ASdependent selectivity of other types of synapse differentiation. Moreover, the mechanism by which specific variants are recruited to distinct synapses during differentiation remains unknown.

An example of the role AS plays in guiding neuronal projections can be seen at the vertebrate midline, where crossing of axons to achieve coordination of the two sides of the body is tightly regulated by highly conserved guidance factors, like the repellent Slit (Dickson 2002).
Analysis of Robo3, a homolog of the Roundabout (Robo) family of chemoreceptors known to bind Slits, is found to be important for initial axonal crossing and subsequent prevention from recrossing the ventral midline during chick nervous system development (Chen et al. 2008). In this recent study, the alternative intron retention of Robo3 pre-mRNA generates two isoforms: Robo3.1 and Robo 3.2. First, Robo3.1 is expressed differentially on the proximal side (ipsilateral) of commissural axons, where it prevents premature midline repulsion by antagonizing Robo1 and Robo2 sensitivity to Slit signaling prior to crossing. Then, Robo3.2 promotes midline repulsion once the growth cone is on the distal (contralateral) side (Fig. $2 F)$. The mechanism involved in the differential expression of the Robo3 isoforms is still unknown. However, it is unlikely that a transcriptional clock is involved in the distinct temporal and spatial expression of Robo3 variants, since RT-PCR analysis suggests both are expressed continuously throughout this developmental time frame. Hence, regulation could entail mRNA transport and local translation, or post-translational control involving the selective trafficking (or degradation) of Robo3 isoforms from proximal and distal segments of the axon (Black and Zipursky 2008; Chen et al. 2008).

While the examples described above highlight the importance of alternatively spliced messages in neuronal connectivity, the role that regulation of AS plays in this process remains somewhat unknown. In the nervous system, developmental splicing patterns are regulated by a diverse array of RBPs such as Tra2 $\beta$, the neuronal 
polypyrimidine tract-binding protein (nPTB), embryonic lethal-abnormal vision (ELAV), Feminizing gene on $X$ (FOX), and neuron-oncological ventral proteins (Nova), among others (Li et al. 2007). These neuronal regulators of AS have been shown to modulate the AS patterns of neurotransmitter receptors, ion channels, post-synaptic density components, and neuronal signaling molecules (Li et aL. 2007). For example, in a recent study, it was shown that Nova, a neuron-specific regulator of AS, is critical for neuromuscular junction (NMJ) formation and physiology by mediating the AS of agrin (Ruggiu et al. 2009), a nerve-derived differentiating factor in mammalian NMJs involved in acetylcholine receptor (AChR) clustering (Sanes et al. 1998). Nova1 and Nova2 knockout (NovaKO) mice are paralyzed and display abnormal AChR clustering and synaptic transmission. Interestingly, even though this study demonstrated that the generation of the neuron-specific agrin isoform $\mathrm{Z}(+)$, by Nova1/2, is essential for AChR assembly and synaptic excitability, NovaKO mice expressing agrin $\mathrm{Z}(+)$ continue to be paralyzed. This suggests that there is an agrin $\left(Z_{+}\right)$independent regulation of motor neuron function by Nova (Ruggiu et al. 2009). Given the current understanding of regulators of AS, it would be interesting to investigate the splicing factors and mechanisms involved in the AS of Dscam1 and Robo3, as well as NRXs and NLs.

\section{mRNA transport and local translation}

In a classical view of the central dogma, mRNA is exported to the cytosol, then it is translated by polyribosomes in the cell body, and de novo proteins are transported to its respective sites of action. During nervous system development, growth cones and synapses need to rapidly change their molecular profiles in order to respond locally to a dynamic extracellular environment, and in turn make decisions regarding their navigation, morphology, and function-often on the order of minutes (Campbell and Holt 2001; Piper et al. 2006; Sutton and Schuman 2006). Several molecular models could account for this cellular response: (1) Input at distal neuritic sites (i.e., growth cones or synapses) could involve the induction of a feedback mechanism to the soma that leads to transcription and translation, then selective protein delivery to the initial site of input, such as in the case of synaptic "tagging" in rat hippocampal and Aplysia sensory neurons (Martin and Kosik 2002). (2) The factors needed for circuit assembly could be expressed constitutively and present in a reversibly inactive state throughout the cell, and could be activated through post-translational modifications such as phosphorylation (Lisman and Zhabotinsky 2001). (3) mRNA could be delivered selectively to subcellular sites of action in neurites, in a reversibly inhibited state, and triggered to locally synthesize protein upon induction. In principal, induction of transcriptional changes (model 1) is responsible for longterm stabilizing effects, while reversible local protein activation (model 2) as well as mRNA transport and local translation (model 3) are likely involved in a more immediate response to neighboring external stimuli. An added advantage to subcellular mRNA localization and translation is that one transcript can promote several rounds of translation, alleviating the energy cost of shuttling proteins independently (Jansen 2001; Martin and Ephrussi 2009). Furthermore, local translation has the benefit of being initially devoid of post-translational modifications that may alter protein function and/or stability. For example, actin polymerization at the growth cone and synapse is crucial for its response to extracellular stimuli (Okamoto et al. 2004; Leung et al. 2006). Hence, modifications to $\beta$-actin such as argynilation and glutathionylation could possibly affect its polymerization dynamics, thereby requiring a naïve pool of actin to promote localized filament formation (Wang et al. 2001; Karakozova et al. 2006; Lin and Holt 2007). Interestingly, in a recent study using high-resolution hybridization techniques, it was found that $71 \%$ of the mRNAs expressed during Drosophila embryogenesis have distinct subcellular localization (Lécuyer et al. 2007). Similarly, microarray analysis of RNA isolated from hippocampal processes identified a large number of mRNAs encoding components of the translational machinery, cytoskeleton, cell adhesion, and post-synaptic apparatus (Poon et al. 2006; Zhong et al. 2006). These studies suggest that, while different molecular models might be involved at different temporal stages of neuronal connectivity, mRNA delivery and local translation likely play a prominent role in network assembly.

To date, our understanding of the mechanisms underlying mRNA localization and function comes from studies of three types of RNA granules: neuronal transport RNPs, processing bodies (P-bodies), and stress granules (Kiebler and Bassell 2006; Bramham et al. 2007). Neuronal transport RNPs are the main vehicle involved in mRNA translocation during neural development, while P-bodies and stress granules mediate translational repression, degradation, and/or storage of mRNA under different physiological conditions. The best-studied molecules present in the neuronal transport RNPs are the zipcode-binding protein 1 (ZBP1), fragile $\mathrm{X}$ mental retardation protein (FMRP), cytoplasmic polyadenylation element-binding protein (CPEB), staufen, survival of motor neuron (SMN), hnRNPA2, and purine-rich elementbinding protein- $\alpha$ (Pur $\alpha$ ) (Kiebler and Bassell 2006).

\section{$Z B P S$}

ZBP1 is an RBP identified for its ability to recognize the "zipcode," a cis-acting element in the $\beta$-actin 3'UTR necessary for delivery of $\beta$-actin mRNA at the leading edge of fibroblasts (Ross et al. 1997). Studies in chick neurons first revealed that ZBP1 also promotes $\beta$-actin localization at developing growth cones, and its activity is important for neurotrophin-induced neurite outgrowth (HL Zhang et al. 2001). Work in Xenopus neurons later described that ZBP1 mediates the asymmetrical localization and translation of $\beta$-actin in growth cones after exposure to gradients of Netrin-1 and BDNF (Fig. 3A; Leung et al. 2006; Yao et al. 2006). Interestingly, brain-derived neurotrophic factor (BDNF) was able to asymmetrically 

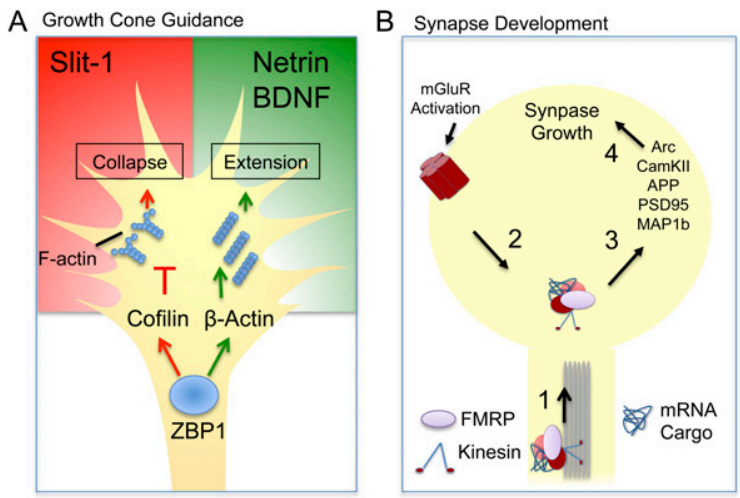

Figure 3. RNA transport and local translation. $(A)$ Illustration of a growth cone exposed to chemoattractant (Netrin and BDNF) and chemorepulsive (Slit-1) cues. ZBP1 regulates the delivery and local translation of $\beta$-Actin and cofilin mRNA during guidance cue-induced growth cone extension or collapse (Leung et al. 2006; Piper et al. 2006; Yao et al. 2006). (B) Schematic of a dendritic spine representing the role of FMRP in synapse morphogenesis. FMRP is involved in the kinesin-dependent transport of mRNA to synaptic sites (1). Activation of metabotropic glutamate receptors (mGluRs) derepresses the FMRP mRNA cargo (2), induces local translation (3), and promotes dendritic spine growth (4) (Dictenberg et al. 2008).

activate Src (Yao et al. 2006), a kinase shown to phosphorylate ZBP1 and promote local $\beta$-actin translation and neurite outgrowth (Huttelmaier et al. 2005). This indicates that ZBP1-containing neuronal transport RNPs are not only involved in transport, but also the reversible translational repression of their cargo mRNAs. Apart from its role in axonal guidance, ZBP1 localizes to dendritic spines of hippocampal neurons and regulates synapse density and structure through the localization, and possibly local translation, of $\beta$-actin (Eom et al. 2003; Tiruchinapalli et al. 2003). ZBP1 also has been shown to bind the mRNA of cofilin, an actin-depolymerizing factor, and mediate Slit2-induced local translation during growth cone collapse (Fig. 3A; Piper et al. 2006). It is likely that ZBP1 functionally transports transcripts other then $\beta$-actin and cofilin. Therefore, it would be interesting to identify other potential targets of ZBP1 during nervous system development.

\section{FMRP}

Mutations in the FMR1 gene result in Fragile X syndrome (FXS), a leading form of heritable mental retardation. FMR1 encodes the FMRP, an RBP containing two hnRNP-K homology domains and an arginine-glycineglycine box (RGG) (Bassell and Warren 2008). In neurons, FMRP localizes to axons and dendrites (Antar et al. 2006), and has been found to selectively transport the mRNA of cytoskeletal, synaptic, and translational regulatory components to distal axonal and synaptic sites (Bassell and Warren 2008). In Drosophila and mouse models for FXS, it has been shown that FMRP is critical for proper synaptic morphogenesis (Nimchinsky et al. 2001; Pan et al. 2004). FMR1 knockout mice exhibit striking defects in dendritic spine morphogenesis, characterized by denser, thinner, and longer post-synaptic spines (Bassell and Warren 2008). In a recent study, it was shown that mRNA transport by FMRP is important for developmental morphologic plasticity (Dictenberg et al. 2008). In this context, regulation of synapse formation involves FMRPmediated mRNA delivery to dendrites, and translational repression of cytoskeletal and signaling components such as map1b, profilin, and camkII (Fig. 3B; YQ Zhang et al. 2001; Reeve et al. 2005; Dictenberg et al. 2008). In addition to its role in the development of synaptic contacts, recent studies also implicate FMRP in axonal motility and guidance (Antar et al. 2006; Li et al. 2009). It was found that FMR1 knockout neurons are not responsive to the protein synthesis-dependent induction of growth cone collapse by the guidance cue Semaphorin3A (Sema3A). Also, Sema3A-induced translation of MAP1B in distal axons was severely reduced in FMR1 mutant animals (Li et al. 2009), suggesting that FMRP regulates either the delivery of the message or its local translation.

\section{Staufen}

Staufen encodes a highly conserved dsRNA-binding protein. In Drosphila, Staufen is best known for selectively localizing bicoid and oskar mRNA in oocytes and prospero mRNA in embryonic neuroblasts. Vertebrates express two isoforms: Staufen1 and Staufen2 (Stau1 and Stau2) (St Johnston 2005). Both Stau isoforms localize to dendritic sites in hippocampal neurons (Kiebler et al. 1999; Tang et al. 2001) and are implicated in translational control at distal synaptic sites. More recently, two independent studies looking at Staul and Stau2-depleted hippocampal neurons found severe deficits in dendritic spine morphology, size, and density (Goetze et al. 2006; Vessey et al. 2008). Depletion of Staul and Stau2 was found to significantly reduce both $\beta$-actin mRNAcontaining RNPs and $\beta$-actin mRNA at dendritic sites, suggesting Staufen regulates the dendritic cytoskeleton. Given that local increase in filamentous acting (F-actin) is required for activity-induced dendritic spine enlargement and potentiation (Okamoto et al. 2004; Honkura et al. 2008), it would be interesting to determine whether Staufen-mediated delivery of $\beta$-actin mRNA is involved in this process. In addition to its late function at the synapse, Staufen may also play a role at earlier stages during neuritic guidance. Given that it is found to be present in axonal processes and colocalizes with $R$ ho $A$ mRNA at the growth cone (Wu et al. 2005), an intriguing possibility might be that Staufen regulates the delivery and/or local translation of RhoA mRNA during Sema3Ainduced growth cone collapse.

\section{CPEB}

CPEB is an RBP involved in the delivery and activitydependent translation of mRNA at axonal and dendritic sites. Drosphila has two paralogs of CPEB (orb and orb2), while vertebrates usually express four (CPEB1-4) (Richter and Klann 2009). Modulation of protein synthesis by 
Loya et al.

CPEB1 (also called CPEB) occurs through the translational inhibition of mRNA containing the CPE sequence. This translational repression is relieved once CPEB is phosphorylated by Aurora kinase or CaMKII (Ule and Darnell 2006). The first evidence that CPEB is involved in patterning the nervous system comes from studies of commissural axons in chick spinal chords. In this study, CPEB was shown to be present at the growth cone and implicated in mediating the localized translation of the guidance receptor EphA2 following axonal midline crossing (Brittis et al. 2002).

More recently, CPEB has been shown to also be critical for regulating synaptic morphogenesis. Using mutants that interfered with CPEB-mediated mRNA transport and protein synthesis, or phosphorylation by Aurora kinase and CamKII, researchers found that CPEB is crucial for dendritic growth in Xenopus tectal neuron denrites (Bestman and Cline 2008), as well as dendritic spine size and density in purkinje cells (Mcevoy et al. 2007). While much is known about the importance of CPEB in the regulation of neuronal circuitry, few functional targets have been identified. Interestingly, neuronspecific actin of Aplysia has been shown to contain CPEs in its $3^{\prime}$ UTR and not only colocalize with CPEB, but also become polyadenylated in an activity-dependent fashion (Liu and Schwartz 2003). Considering the function of neuronal transport RNPs reviewed here, perhaps regulation of the delivery and deployment of the neuronal cytoskeleton represents a common theme we are just beginning to understand.

Of note, recent studies show that nonsense-mediated decay (NMD) is also involved in regulating the expression and localization of proteins at the synapse (for a review on NMD, see Stalder and Muhlemann 2008; Rebbapragada and Lykke-Anderson 2009). For instance, the exon junction complex (EJC) factor eIF4AIII regulates the dendritically localized protein Arc (activity-regulated cytoskeleton associated) to modulate glutamate receptor availability during synaptic plasticity (Giorgi et al. 2007). Given that many transcripts are bioinformatically predicted to be natural targets of NMD (Giorgi et al. 2007), it would be interesting to study the role this mechanism plays during axonal patterning and synapse formation.

\section{miRNA}

miRNA machinery and neuronal development

miRNAs are short, $\sim 20$ - to 24-nucleotide (nt) noncoding RNAs known to play vital roles in nervous system development, physiology, and disease (Bushati and Cohen 2007). miRNAs regulate gene expression by complementary binding to target mRNA, most prominently in their 3'UTR, and promoting RNA instability and/or inhibition of effective protein synthesis (Eulalio et al. 2008). Briefly, miRNA biogenesis starts in the nucleus where the RNase III endonuclease Drosha and its binding partner pasha/ DGRC8 catalyze the first cleavage of the primary miRNA transcript. Then, the cytoplasmic RNase III Dicer generates the $\sim 20$ - to 24-nt duplex that is subsequently loaded to the RNA-induced silencing complex (RISC) for mRNA recognition and suppression (Fig. 4A; Du and Zamore 2005). Studies using maternal-zygotic or conditional mutants of Dicer revealed gross morphological defects in nervous system development (Giraldez et al. 2005; Cuellar et al. 2008; Davis et al. 2008). Since then, tissuespecific inhibition of the miRNA pathway as well as depletion of individual miRNAs has shown with greater clarity the importance of miRNA in patterning neuronal connectivity. Notably, recent technologies using highthroughput sequencing of RNAs isolated from immunoprecipitation (HITS-CLIP), combined with bioinformatics, allow for a detailed map of functional mRNAmiRNA interactions that are certain to expand our understanding of miRNA regulation of nervous system development (Chi et al. 2009).

A recent study using a MARCM-based forward genetic screen in Drosophila identified the miRNA processing proteins pasha/DGRC8 and Dicer1 as crucial components in the establishment of wiring specificity (Berdnik et al. 2008). The fly olfactory system is characterized by highly stereotyped neuronal connections. Each projection
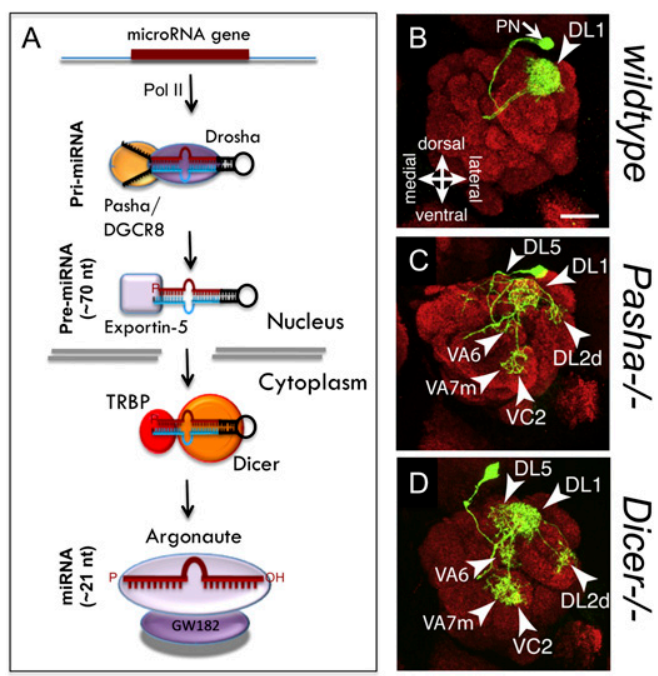

Figure 4. miRNA regulation of neuronal connectivity. $(A)$ miRNA biogenesis pathway. miRNA are regularly transcribed by RNA Pol II, then the primary miRNA (pri-miRNA) is processed by the RNase III endonuclease Drosha and the RBP Pasha/DGRC8 into the $\sim 70$-nt pre-miRNA. Exportin-5 exports the pre-miRNA to the cytoplasm, where it is cleaved by the another RNase III endonuclease (Dicer) and the RBP TRBP/ loquacious into the $\sim 21$ duplex miRNA. This duplex is loaded into the argonaute- and GW182-containing RISC, where it then recognizes target mRNA and promotes destabilization or translational repression. $(B-D)$ Representative images of Drosophila single-cell MARCM clones of olfactory PNs targeting glomeruli in the antennal lobe; images reprinted from Berdnik et al. (2008), (C) 2008, with permission from Elsevier. (B) In a wild-type background, anterodorsal PNs (adPNs) extend dendrites and specifically target the DL1 glomerulus. In Pasha $(C)$ and Dicer $(D)$ mutants, adPN innervation of DL1 is reduced, and mistargeting of DL5, DL2d, VA6, VA7m, and VC2 glomeruli is observed (Berdnik et al. 2008). 
neuron $(\mathrm{PN})$ targets dendrites to a specific glomerulus in the antennal lobe and stereotypically sends axons to higher brain centers such as the lateral horn (LH) via the mushroom body calyx (MBC). Analysis of postmitotic single- and multiple-cell MARCM clones with homozygous mutations for pasha and dicer1 showed a drastic reduction in dendritic density at most glomeruli, as well as significant mistargeting of $\mathrm{PN}$ dendrites to their corresponding glomerulus (Fig. 4B-D; Berdnik et al. 2008). In addition, pasha and dicer 1 mutants exhibited decreased growth and morphological abnormalities in axonal terminations of PN at both the MBCs and LHs. This study provided the first conclusive evidence that the miRNA pathway is necessary for organizing precise neural networks. Nevertheless, the specific miRNA responsible for this process remain to be identified.

\section{Understanding miRNA regulation of synaptic connectivity}

Interactions between miRNA and their targets are often classified as a "switch," "tuning," or "neutral" (Bartel and Chen 2004; Flynt and Lai 2008). A "switch" interaction is characterized by a miRNA reducing the target protein activity to a negligible level. This differs from "tuning" interactions, which result in the fine modulation of target protein levels to an optimal range for a given physiological and/or developmental state. "Neutral" targets are usually species-specific interactions that have neither a positive nor negative effect on the cell. Analysis of dendrite and synapse formations has revealed that both miRNA "tuning" and "switching" mechanisms are involved in regulating proper synaptic connectivity.

During neuronal development, increases in dendritic arbor complexity have been shown to be an important determinant of synaptic number, size, and function. Transient depolarization, or exposure to neurotrophins, promotes this dendritic arbor morphogenesis (Wong and Ghosh 2002; Matsuzaki et al. 2004). Recent studies have revealed the importance that neuron-enriched miR-132 and miR-134 have in the activity-regulated rapid response changes of dendritic elaboration (Vo et al. 2005; Wayman et al. 2008; Fiore et al. 2009). For example, activitydependent decrease of the Rho family GTPase-activating protein p250GAP by miR-132 has been shown to be responsible for the observed increase in dendritic complexity in hippocampal neurons (Wayman et al. 2008). In a similar fashion, miR-134 regulates pumilio2, an RBP involved in mRNA transport and translational inhibition, to promote activity-dependent dendritic arbor plasticity (Fiore et al. 2009). Although analogous in phenotypic output, the miRNA-target interactions between miR132-p250GAP and miR-134-pumilio2 are strikingly different. For example, miR-132 up-regulation or inhibition of p250GAP was sufficient to mimic the activity-induced increases in dendritic growth (Wayman et al. 2008), suggesting that miR-132 acts as a regulatory "switch" and turns off p250GAP upon induction of neuronal activity. On the contrary, neither overexpression of miR-134 nor siRNA-mediated inhibition of pumilio2 in the presence or absence of an activity-inducing stimulus was able to increase dendritic complexity (Fiore et al. 2009). This indicates that "tuning" of pumilio2 by miR134 is necessary for activity-dependent branch growth.

In addition to being involved in neuritic branch elaboration, miRNA have been shown recently to play an intricate role in dendritic spine development. In a seminal study, miR-134 was identified as a spine-enriched negative regulator of dendritic spine size through the compartmentalized "tuning" of Limk1, a regulator of actin filament dynamics (Schratt et al. 2006). Translational repression of Limk1 was relieved by exposure to the neurotrophin BDNF, highlighting the functional versatility that miRNA introduce into a neural network by regulating de novo protein synthesis in an activity-dependent and spatially restricted fashion. Further analysis of synapse-enriched miRNA revealed another critical regulator of spine structure (Siegel et al. 2009). Inhibition of miR-138 showed significant increase in dendritic spine volume, whereas overexpression of miR-138 exhibited a striking decrease. miR-138 was found to regulate synapse formation by modulating the levels of acyl protein thioesterase 1 (APT1), an enzyme known to depalmitoylate synaptically localized proteins, including the $\alpha_{13}$ subunits of G proteins $\left(G \alpha_{13}\right)$. Notably, overexpression of $G \alpha_{13}$ was able to rescue the growth-promoting effects of miR-138 inhibition. Given that $\mathrm{G} \alpha_{13}$ recruitment to the membrane activates the RhoA signaling pathway, it suggests that the spine-shrinking capacity of miR-138 is due to Rhomediated regulation of the actin cytoskeleton (Schratt 2009). These studies reveal an underlying trend in which the dendritic spine specifically uses miRNA to locally regulate morphology and function through the precise modulation of actin cytoskeletal dynamics.

Further evidence suggesting that miRNA control synapse morphogenesis through regulation of the actin cytoskeleton comes from recent studies of the Drosophila NMJ. Using a novel technology for tissue-specific silencing, it was shown that miR-8 strongly promotes NMJ growth by modulating the protein levels of Enabled (Ena), a regulator of actin dynamics, exclusively in the post-synaptic space, despite prominent expression of miR-8 and Ena on both sides of the synapse (Loya et al. 2009). This illustrates how miRNA can function tissuespecifically to regulate synapse development even when expressed across synaptic compartments. Additional studies on the Drosophila NMJ show that Let-7 is involved in regulating synapse maturation and growth (Caygill and Johnston 2008; Sokol et al. 2008) through the targeting of abrubt $(\mathrm{ab})$, a nuclear protein known for its functions in NMJ targeting and dendritic arborization (Caygill and Johnston 2008). Apart from regulation of NMJ morphology and maturation, miRNA have also been shown to control the physiological architecture of the synapse by modulating the abundance and availability of glutamate receptor (GluR) levels at post-synaptic sites (Karr et al. 2009).

Signaling between pre- and post-synaptic membranes is essential to coordinate synaptic morphogenesis, growth, and function in order to complement presynaptic input 
with the necessary post-synaptic output (Keshishian and Kim 2004). In an elegant study of worm NMJs, the muscle-specific miR-1 was shown to regulate both postsynaptic sensitivity, by directly targeting subunits of the nicotinic AChR (nAChR), and presynaptic ACh release, through a MEF2-dependent retrograde signal mediated by the synaptic vesicle protein RAB-3 (Simon et al. 2008). Acute activation of nAChRs was able to induce this MEF2-dependent retrograde response, suggesting that miR-1 functions to finely tune synaptic transmission by coupling changes in post-synaptic activity with modulation of presynaptic function. Further evidence of miRNA acting as regulatory nodes of trans-synaptic regulation comes from a recent study of dendritic scaling of Drosphila sensory neurons (Parrish et al. 2009). Following appropriate targeting and coverage of receptive fields, axonal and dendritic arbors need to increase in size proportional to their underlying substrate in order to ensure appropriate synaptic connectivity and coverage as the animal grows; this phenomena is known as dendritic scaling. Analysis of scaling growth in the Drosophila peripheral nervous system (PNS), shows that the miRNA bantam regulates growth inhibitory signals in peripheral sensory neurons from their underlying epithelia (Parrish et al. 2009). This study demonstrates clearly that bantam functions nonautonomously in epithelial cells by repressing the growth signal Akt in PNS sensory neurons and ensuring appropriate neurite expansion during animal growth (Parrish et al. 2009).

Although our knowledge of the role miRNAs play in synapse development increases rapidly, our understanding of the importance of individual miRNAs in axonal guidance is still quite primitive. To date, we know that the neuron-specific miR-338 locally regulates the protein levels of cytochrome c oxidase IV (COXIV) in the axons of sympathetic neurons, and consequently controls energy output during neuronal development (Aschrafi et al. 2008). However, whether exposure to guidance cues is able to locally regulate protein levels at the growth cone and direct its navigation in a miRNA-dependent fashion is an exciting topic for future studies.

\section{Conclusion}

In summary, the diversity and specificity of neuronal connectivity is regulated extensively by a post-transcriptional toolkit composed of AS, the RNA transport machinery, and miRNAs. AS has shown how a single gene locus can give rise to a wide range of proteins with differential functional and structural properties that work in concert to enable growth cones to respond to intermediate targets, stereotype neuritic branch patterns, and differentiate synaptic connections. However, the mechanism regulating the inclusion or exclusion of certain isoforms in a given cell type or developmental time, as well as the mechanisms involved in transporting these specific variants to their sites of action, remain largely unknown.

Studies on neuronal transport RNPs have identified a series of well-conserved RBPs that recognize specific pools of mRNA and regulate their selective subcellular localization and local translation. It bears pointing out that most of the work described here was performed in primary tissue culture systems. Thus, new technologies able to visualize local protein synthesis (Leung and Holt 2008; Wang et al. 2009) in vivo will enable a more direct analysis of the role mRNA transport and localization play in nervous system development.

miRNA-mediated silencing has emerged as a highly versatile post-transcriptional mechanism able to modulate neuronal connectivity by acting as either a regulatory "switch" or "rheostat" of gene expression. It is interesting to note that both neuronal RNPs and miRNA pathways converge substantially on the direct regulation of cytoskeletal dynamics during growth cone navigation and/or development of synaptic structure and function, alluding to a multilevel regulatory mechanism. Recent biochemical and genetic studies have implied that components of the neuronal transport granule, like FMRP and Staufen, interact with elements of the miRNA pathway such as Argonaute and Dicer proteins (Caudy et al. 2002; Ishizuka et al. 2002; Jin et al. 2004; Barbee et al. 2006). However, future studies are necessary to directly assess the role of the neuronal transport granule and the function of specific miRNA during nervous system development. Conversely, during neuronal differentiation, miR-124 has been shown to target PTB protein $1 / 2$ (PTBP1/2), and regulate the switch between nonneuronal and neuronal AS (Makeyev and Maniatis 2008). Hence, a greater understanding of how this post-transcriptional toolkit interacts with each other to assemble neural networks is an exciting new frontier for neurobiology.

\section{Acknowledgments}

We thank Regina Ragasa for valuable feedback on the manuscript and figures. We were supported by grant NS40043.

\section{Note added in proof}

Most recently, studies in hippocampal neurons found that FMRP is associated with several specific miRNAs (Edbauer et al. 2010). It was shown that, of the FMRP-associated miRNAs, miR-132 and miR-125b differentially affect dendritic spine morphology in an FMRP-dependent fashion. In addition, negative regulation of NMDA receptor subunit NR2A involved both FMRP activity and miR-125b targeting of the NR2A 3'UTR. This indicates that FMRP is an important coregulator of miRNA function during synapse development, confirming early proposals that RBPs interact with the miRNA pathway in neurons.

\section{References}

Antar LN, Li C, Zhang H, Carroll RC, Bassell GJ. 2006. Local functions for FMRP in axon growth cone motility and activity-dependent regulation of filopodia and spine synapses. Mol Cell Neurosci 32: 37-48.

Aschrafi A, Schwechter AD, Mameza MG, Natera-Naranjo O, Gioio AE, Kaplan BB. 2008. MicroRNA-338 regulates local cytochrome c oxidase IV mRNA levels and oxidative phosphorylation in the axons of sympathetic neurons. I Neurosci 28: 12581-12590.

Barbee SA, Estes PS, Cziko AM, Hillebrand J, Luedeman RA, Coller JM, Johnson N, Howlett IC, Geng C, Ueda R, et al. 
2006. Staufen- and FMRP-containing neuronal RNPs are structurally and functionally related to somatic P bodies. Neuron 52: 997-1009.

Bartel DP, Chen CZ. 2004. Micromanagers of gene expression: The potentially widespread influence of metazoan microRNAs. Nat Rev Genet 5: 396-400.

Bassell GJ, Warren ST. 2008. Fragile X syndrome: Loss of local mRNA regulation alters synaptic development and function. Neuron 60: 201-214.

Berdnik D, Fan AP, Potter CI, Luo L. 2008. MicroRNA processing pathway regulates olfactory neuron morphogenesis. Curr Biol 18: 1754-1759.

Bestman J, Cline HT. 2008. The RNA binding protein CPEB regulates dendrite morphogenesis and neuronal circuit assembly in vivo. Proc Natl Acad Sci 105: 20494-20499.

Black DL, Zipursky SL. 2008. To cross or not to cross: Alternatively spliced forms of the Robo3 receptor regulate discrete steps in axonal midline crossing. Neuron 58: 297-298.

Boucard AA, Chubykin AA, Comoletti D, Taylor P, Südhof T. 2005. A splice code for trans-synaptic cell adhesion mediated by binding of neuroligin 1 to $\alpha$ - and $\beta$-neurexins. Neuron 48: 229-236.

Bramham CR, Bramham CR, Wells DG, Wells DG. 2007. Dendritic mRNA: Transport, translation and function. Nat Rev Neurosci 8: 776-789.

Brittis PA, Lu Q, Flanagan JG. 2002. Axonal protein synthesis provides a mechanism for localized regulation at an intermediate target. Cell 110: 223-235.

Bushati N, Cohen SM. 2007. MicroRNA functions. Annu Rev Cell Dev Biol 23: 175-205.

Campbell DS, Holt CE. 2001. Chemotropic responses of retinal growth cones mediated by rapid local protein synthesis and degradation. Neuron 32: 1013-1026.

Caudy AA, Myers M, Hannon GJ, Hammond SM. 2002. Fragile $\mathrm{X}$-related protein and VIG associate with the RNA interference machinery. Genes \& Dev 16: 2491-2496.

Caygill E, Johnston L. 2008. Temporal regulation of metamorphic processes in Drosophila by the let-7 and miR-125 heterochronic microRNAs. Curr Biol 18: 943-950.

Chen Z, Gore BB, Long H, Ma L, Tessier-Lavigne M. 2008. Alternative splicing of the Robo3 axon guidance receptor governs the midline switch from attraction to repulsion. Neuron 58: 325-332.

Chi SW, Zang JB, Mele A, Darnell RB. 2009. Argonaute HITSCLIP decodes microRNA-mRNA interaction maps. Nature 460: 479-486.

Chih B, Gollan L, Scheiffele P. 2006. Alternative splicing controls selective trans-synaptic interactions of the neuroliginneurexin complex. Neuron 51: 171-178.

Clark TA, Schweitzer AC, Chen TX, Staples MK, Lu G, Wang H, Williams A, Blume JE. 2007. Discovery of tissue-specific exons using comprehensive human exon microarrays. Genome Biol 8: R64. doi: 10.1186/gb-2007-8-04-r64.

Craig AM, Kang Y. 2007. Neurexin-neuroligin signaling in synapse development. Curr Opin Neurobiol 17: 43-52.

Cuellar TL, Davis TH, Nelson PT, Loeb GB, Harfe BD, Ullian EM, McManus MT. 2008. Dicer loss in striatal neurons produces behavioral and neuroanatomical phenotypes in the absence of neurodegeneration. Proc Natl Acad Sci 105: 5614-5619.

Davis TH, Cuellar TL, Koch SM, Barker AJ, Harfe BD, McManus MT, Ullian EM. 2008. Conditional loss of dicer disrupts cellular and tissue morphogenesis in the cortex and hippocampus. J Neurosci 28: 4322-4330.

Dickson BJ. 2002. Molecular mechanisms of axon guidance. Science 298: 1959-1964.
Dictenberg JB, Swanger SA, Antar LN, Singer RH, Bassell GJ. 2008. A direct role for FMRP in activity-dependent dendritic mRNA transport links filopodial-spine morphogenesis to fragile X syndrome. Dev Cell 14: 926-939.

Du T, Zamore PD. 2005. microPrimer: The biogenesis and function of microRNA. Development 132: 4645-4652.

Edbauer D, Neilson JR, Foster KA, Wang CF, Seeburg DP, Batterton MN, Tada T, Dolan BM, Sharp PA, Sheng M. 2010. Regulation of synaptic structure and function by FMRP-associated microRNAs miR-125b and miR-132. Neuron 65: 373-384.

Eom T, Antar LN, Singer RH, Bassell GJ. 2003. Localization of a $\beta$-actin messenger ribonucleoprotein complex with zipcode-binding protein modulates the density of dendritic filopodia and filopodial synapses. J Neurosci 23: 10433-10444.

Eulalio A, Huntzinger E, Izaurralde E. 2008. Getting to the root of miRNA-mediated gene silencing. Cell 132: 9-14.

Fiore R, Khudayberdiev S, Christensen M, Siegel G, Flavell SW, Kim T, Greenberg ME, Schratt G. 2009. Mef2-mediated transcription of the miR379-410 cluster regulates activitydependent dendritogenesis by fine-tuning Pumilio2 protein levels. $E M B O$ J 28: 697-710.

Flanagan JG. 2006. Neural map specification by gradients. Curr Opin Neurobiol 16: 59-66.

Flanagan JG, Vanderhaeghen P. 1998. The ephrins and eph receptors in neural development. Annu Rev Neurosci 21: 309-345.

Flynt AS, Lai EC. 2008. Biological principles of microRNAmediated regulation: Shared themes amid diversity. Nat Rev Genet 9: 831-842.

Garbe DS, Bashaw GJ. 2004. Axon guidance at the midline: From mutants to mechanisms. Crit Rev Biochem Mol Biol 39: 319-341.

Giorgi C, Yeo GW, Stone ME, Katz DB, Burge C, Turrigiano G, Moore MJ. 2007. The EJC factor eIF4AIII modulates synaptic strength and neuronal protein expression. Cell 130: 179-191.

Giraldez AJ, Cinalli RM, Glasner ME, Enright AJ, Thomson JM, Baskerville S, Hammond SM, Bartel DP, Schier AF. 2005. MicroRNAs regulate brain morphogenesis in zebrafish. Science 308: 833-838.

Goetze B, Tuebing F, Xie Y, Dorostkar MM, Thomas S, Pehl U, Boehm S, Macchi P, Kiebler MA. 2006. The brain-specific double-stranded RNA-binding protein Staufen2 is required for dendritic spine morphogenesis. J Cell Biol 172: 221-231.

Hattori D, Demir E, Kim HW, Viragh E, Zipursky SL, Dickson BJ. 2007. Dscam diversity is essential for neuronal wiring and self-recognition. Nature 449: 223-227.

Hattori D, Millard SS, Wojtowicz WM, Zipursky SL. 2008. Dscam-mediated cell recognition regulates neural circuit formation. Annu Rev Cell Dev Biol 24: 597-620.

Hattori D, Chen Y, Matthews BJ, Salwinski L, Sabatti C, Grueber WB, Zipursky SL. 2009. Robust discrimination between self and non-self neurites requires thousands of Dscam1 isoforms. Nature 461: 644-648.

Honkura N, Matsuzaki M, Noguchi J, Ellis-Davies G, Kasai H. 2008. The subspine organization of actin fibers regulates the structure and plasticity of dendritic spines. Neuron 57: 719729.

Huttelmaier S, Zenklusen D, Lederer M, Dictenberg J, Lorenz M, Meng X, Bassell GJ, Condeelis J, Singer RH. 2005. Spatial regulation of $\beta$-actin translation by src-dependent phosphorylation of ZBP1. Nature 438: 512-515.

Ishizuka A, Siomi MC, Siomi H. 2002. A Drosophila fragile X protein interacts with components of RNAi and ribosomal proteins. Genes \& Dev 16: 2497-2508.

Jansen RP. 2001. mRNA localization: Message on the move. Nat Rev Mol Cell Biol 2: 247-256. 
Jin P, Zarnescu DC, Ceman S, Nakamoto M, Mowrey J, Jongens TA, Nelson DL, Moses K, Warren ST. 2004. Biochemical and genetic interaction between the fragile $\mathrm{X}$ mental retardation protein and the microRNA pathway. Nat Neurosci 7: 113-117.

Johnson JM, Castle J, Garrett-Engele P, Kan Z, Loerch PM, Armour CD, Santos R, Schadt EE, Stoughton R, Shoemaker DD. 2003. Genome-wide survey of human alternative premRNA splicing with exon junction microarrays. Science 302: 2141-2144.

Johnson MB, Kawasawa YI, Mason CE, Krsnik Z, Coppola G, Bogdanovic D, Geschwind DH, Mane SM, State MW, Sestan N. 2009. Functional and evolutionary insights into human brain development through global transcriptome analysis. Neuron 62: 494-509.

Karakozova M, Kozak M, Wong CC, Bailey AO, Yates JR 3rd, Mogilner A, Zebroski H, Kashina A. 2006. Arginylation of $\beta$-actin regulates actin cytoskeleton and cell motility. Science 313: 192-196.

Karlstrom RO, Trowe T, Bonhoeffer F. 1997. Genetic analysis of axon guidance and mapping in the zebrafish. Trends Neurosci 20: 3-8.

Karr J, Vagin V, Chen K, Ganesan S, Olenkina O, Gvozdev V, Featherstone DE. 2009. Regulation of glutamate receptor subunit availability by microRNAs. J Cell Biol 185: 685-697.

Keshishian H, Kim YS. 2004. Orchestrating development and function: Retrograde BMP signaling in the Drosophila nervous system. Trends Neurosci 27: 143-147.

Kiebler MA, Bassell GJ. 2006. Neuronal RNA granules: Movers and makers. Neuron 51: 685-690.

Kiebler MA, Hemraj I, Verkade P, Kohrmann M, Fortes P, Marion RM, Ortin J, Dotti CG. 1999. The mammalian staufen protein localizes to the somatodendritic domain of cultured hippocampal neurons: Implications for its involvement in mRNA transport. I Neurosci 19: 288-297.

Lécuyer E, Yoshida H, Parthasarathy N, Alm C, Babak T, Cerovina T, Hughes TR, Tomancak P, Krause HM. 2007. Global analysis of mRNA localization reveals a prominent role in organizing cellular architecture and function. Cell 131: 174-187.

Leung K, Holt CE. 2008. Live visualization of protein synthesis in axonal growth cones by microinjection of photoconvertible kaede into Xenopus embryos. Nat Protoc 3: 1318-1327.

Leung K, van Horck F, Lin AC, Allison R, Standart N, Holt CE. 2006. Asymmetrical $\beta$-actin mRNA translation in growth cones mediates attractive turning to netrin-1. Nat Neurosci 9: 1247-1256.

Li Q, Lee JA, Black DL. 2007. Neuronal regulation of alternative pre-mRNA splicing. Nat Rev Neurosci 8: 819-831.

Li C, Bassell GJ, Sasaki Y. 2009. Fragile X mental retardation protein is involved in protein synthesis-dependent collapse of growth cones induced by semaphorin-3A. Front Neural Circuits. 3: 11. doi: 10.3389/neuro.4.011.2009.

Lin AC, Holt CE. 2007. Local translation and directional steering in axons. $E M B O J$ 26: 3729-3736.

Lipscombe D. 2005. Neuronal proteins custom designed by alternative splicing. Curr Opin Neurobiol 15: 358-363.

Lisman JE, Zhabotinsky AM. 2001. A model of synaptic memory: A CaMKII/PP1 switch that potentiates transmission by organizing an AMPA receptor anchoring assembly. Neuron 31: 191-201.

Liu J, Schwartz JH. 2003. The cytoplasmic polyadenylation element binding protein and polyadenylation of messenger RNA in aplysia neurons. Brain Res 959: 68-76.

Loya CM, Lu CS, Van Vactor D, Fulga TA. 2009. Transgenic microRNA inhibition with spatiotemporal specificity in intact organisms. Nat Methods 6: 897-903.
Makeyev EV, Maniatis T. 2008. Multilevel regulation of gene expression by microRNAs. Science 319: 1789-1790.

Manitt C, Nikolakopoulou AM, Almario DR, Nguyen SA, Cohen-Cory S. 2009. Netrin participates in the development of retinotectal synaptic connectivity by modulating axon arborization and synapse formation in the developing brain. J Neurosci 29: 11065-11077.

Martin KC, Ephrussi A. 2009. mRNA localization: Gene expression in the spatial dimension. Cell 136: 719-730.

Martin KC, Kosik KS. 2002. Synaptic tagging-Who's it? Nat Rev Neurosci 3: 813-820.

Matsuzaki M, Honkura N, Ellis-Davies G, Kasai H. 2004. Structural basis of long-term potentiation in single dendritic spines. Nature 429: 761-766.

Mcevoy M, Cao G, Llopis PM, Kundel M, Jones K, Hofler C, Shin C, Wells DG. 2007. Cytoplasmic polyadenylation element binding protein 1-mediated mRNA translation in purkinje neurons is required for cerebellar long-term depression and motor coordination. J Neurosci 27: 6400-6411.

Nilsen TW, Graveley BR. 2010. Expansion of the eukaryotic proteome by alternative splicing. Nature 463: 457-463.

Nimchinsky EA, Oberlander AM, Svoboda K. 2001. Abnormal development of dendritic spines in FMR1 knock-out mice. J Neurosci 21: 5139-5146.

Okamoto K, Nagai T, Miyawaki A, Hayashi Y. 2004. Rapid and persistent modulation of actin dynamics regulates postsynaptic reorganization underlying bidirectional plasticity. Nat Neurosci 7: 1104-1112.

Pan L, Zhang YQ, Woodruff E, Broadie K. 2004. The Drosophila fragile $\mathrm{X}$ gene negatively regulates neuronal elaboration and synaptic differentiation. Curr Biol 14: 1863-1870.

Parrish J, Xu P, Kim C, Jan L, Jan Y. 2009. The microRNA bantam functions in epithelial cells to regulate scaling growth of dendrite arbors in Drosophila sensory neurons. Neuron 63: 788-802.

Piper M, Anderson R, Dwivedy A, Weinl C, van Horck F, Leung KM, Cogill E, Holt C. 2006. Signaling mechanisms underlying Slit2-induced collapse of Xenopus retinal growth cones. Neuron 49: 215-228.

Poon MM, Choi S, Jamieson CA, Geschwind DH, Martin KC. 2006. Identification of process-localized mRNAs from cultured rodent hippocampal neurons. I Neurosci 26: 13390-13399.

Rebbapragada I, Lykke-Andersen J. 2009. Execution of nonsensemediated mRNA decay: What defines a substrate? Curr Opin Cell Biol 21: 394-402.

Reeve SP, Bassetto L, Genova GK, Kleyner Y, Leyssen M, Jackson FR, Hassan BA. 2005. The Drosophila fragile X mental retardation protein controls actin dynamics by directly regulating profilin in the brain. Curr Biol 15: 1156-1163.

Richter J, Klann E. 2009. Making synaptic plasticity and memory last: Mechanisms of translational regulation. Genes \& Dev 23: 1-11.

Ross AF, Oleynikov Y, Kislauskis EH, Taneja KL, Singer RH. 1997. Characterization of a $\beta$-actin mRNA zipcode-binding protein. Mol Cell Biol 17: 2158-2165.

Ruggiu M, Herbst R, Kim N, Jevsek M, Fak JJ, Mann MA, Fischbach G, Burden SJ, Darnell RB. 2009. Rescuing Z+ agrin splicing in nova null mice restores synapse formation and unmasks a physiologic defect in motor neuron firing. Proc Natl Acad Sci 106: 3513-3518.

Sanes JR, Apel ED, Gautam M, Glass D, Grady RM, Martin PT, Nichol MC, Yancopoulos GD. 1998. Agrin receptors at the skeletal neuromuscular junction. Ann N Y Acad Sci 841: 1-13.

Schmucker D, Chen B. 2009. Dscam and DSCAM: Complex genes in simple animals, complex animals yet simple genes. Genes \& Dev 23: 147-156. 
Schmucker D, Clemens JC, Shu H, Worby CA, Xiao J, Muda M, Dixon JE, Zipursky SL. 2000. Drosophila dscam is an axon guidance receptor exhibiting extraordinary molecular diversity. Cell 101: 671-684.

Schratt G. 2009. MicroRNAs at the synapse. Nat Rev Neurosci 10: $842-849$.

Schratt GM, Tuebing F, Nigh EA, Kane CG, Sabatini ME, Kiebler M, Greenberg ME. 2006. A brain-specific microRNA regulates dendritic spine development. Nature 439: 283-289.

Siegel G, Obernosterer G, Fiore R, Oehmen M, Bicker S, Christensen M, Khudayberdiev S, Leuschner PF, Busch C, Kane C, et al. 2009. A functional screen implicates microRNA-138-dependent regulation of the depalmitoylation enzyme APT1 in dendritic spine morphogenesis. Nat Cell Biol 11: 705-716.

Simon DJ, Madison JM, Conery AL, Thompson-Peer K, Soskis M, Ruvkun GB, Kaplan JM, Kim JK. 2008. The microRNA miR-1 regulates a MEF-2-dependent retrograde signal at neuromuscular junctions. Cell 133: 903-915.

Sokol NS, Xu P, Jan YN, Ambros V. 2008. Drosophila let-7 microRNA is required for remodeling of the neuromusculature during metamorphosis. Genes \& Dev 22: 1591-1596.

Speese SD, Budnik V. 2007. Wnts: Up-and-coming at the synapse. Trends Neurosci 30: 268-275.

Sperry RW. 1963. Chemoaffinity in the orderly growth of nerve fiber patterns and connections. Proc Natl Acad Sci 50: 703710.

St Johnston D. 2005. Moving messages: The intracellular localization of mRNAs. Nat Rev Mol Cell Biol 6: 363-375.

Stalder L, Muhlemann O. 2008. The meaning of nonsense. Trends Cell Biol 18: 315-321.

Sutton MA, Schuman EM. 2006. Dendritic protein synthesis, synaptic plasticity, and memory. Cell 127: 49-58.

Tang SJ, Meulemans D, Vazquez L, Colaco N, Schuman E. 2001. A role for a rat homolog of staufen in the transport of RNA to neuronal dendrites. Neuron 32: 463-475.

Tiruchinapalli DM, Oleynikov Y, Kelic S, Shenoy SM, Hartley A, Stanton PK, Singer RH, Bassell GJ. 2003. Activitydependent trafficking and dynamic localization of zipcode binding protein 1 and $\beta$-actin mRNA in dendrites and spines of hippocampal neurons. J Neurosci 23: 3251-3261.

Ule J, Darnell RB. 2006. RNA binding proteins and the regulation of neuronal synaptic plasticity. Curr Opin Neurobiol 16: $102-110$.

Vessey JP, Macchi P, Stein JM, Mikl M, Hawker KN, Vogelsang P, Wieczorek K, Vendra G, Riefler J, Tübing F, et al. 2008. A loss of function allele for murine Staufen1 leads to impairment of dendritic Staufen1-RNP delivery and dendritic spine morphogenesis. Proc Natl Acad Sci 105: 16374-1637.

Vo N, Klein ME, Varlamova O, Keller DM, Yamamoto T, Goodman RH, Impey S. 2005. A cAMP-response element binding protein-induced microRNA regulates neuronal morphogenesis. Proc Natl Acad Sci 102: 16426-16431.

Wang J, Boja ES, Tan W, Tekle E, Fales HM, English S, Mieyal JJ, Chock PB. 2001. Reversible glutathionylation regulates actin polymerization in A431 cells. J Biol Chem 276: 47763-47766.

Wang ET, Sandberg R, Luo S, Khrebtukova I, Zhang L, Mayr C, Kingsmore SF, Schroth GP, Burge CB. 2008. Alternative isoform regulation in human tissue transcriptomes. Nature 456: $470-476$.

Wang DO, Kim SM, Zhao Y, Hwang H, Miura SK, Sossin WS, Martin KC. 2009. Synapse- and stimulus-specific local translation during long-term neuronal plasticity. Science 324: 1536-1540.

Wayman GA, Davare M, Ando H, Fortin D, Varlamova O, Cheng HY, Marks D, Obrietan K, Soderling TR, Goodman
RH, et al. 2008. An activity-regulated microRNA controls dendritic plasticity by down-regulating p250GAP. Proc Natl Acad Sci 105: 9093-9098.

Williams RW, Herrup K. 1988. The control of neuron number. Annu Rev Neurosci 11: 423-453.

Wong RO, Ghosh A. 2002. Activity-dependent regulation of dendritic growth and patterning. Nat Rev Neurosci 3: 803812 .

Wu KY, Hengst U, Hengst U, Cox LJ, Cox LJ, Macosko EZ, Macosko EZ, Jeromin A, Jeromin A, Urquhart ER, et al. 2005. Local translation of RhoA regulates growth cone collapse. Nature 436: 1020-1024.

Yao J, Sasaki Y, Wen Z, Bassell GJ, Zheng JQ. 2006. An essential role for $\beta$-actin mRNA localization and translation in $\mathrm{Ca}^{2+}$. dependent growth cone guidance. Nat Neurosci 9: 12651273.

Zhan XL, Clemens JC, Neves G, Hattori D, Flanagan JJ, Hummel T, Vasconcelos ML, Chess A, Zipursky SL. 2004. Analysis of dscam diversity in regulating axon guidance in Drosophila mushroom bodies. Neuron 43: 673-686.

Zhang HL, Eom T, Oleynikov Y, Shenoy SM, Liebelt DA, Dictenberg JB, Singer RH, Bassell GJ. 2001. Neurotrophininduced transport of a $\beta$-actin mRNP complex increases $\beta$-actin levels and stimulates growth cone motility. Neuron 31: 261-275.

Zhang YQ, Bailey AM, Matthies HJ, Renden RB, Smith MA, Speese SD, Rubin GM, Broadie K. 2001. Drosophila fragile $\mathrm{X}$-related gene regulates the MAP1B homolog futsch to control synaptic structure and function. Cell 107: 591-603.

Zhong J, Zhang T, Bloch LM. 2006. Dendritic mRNAs encode diversified functionalities in hippocampal pyramidal neurons. BMC Neurosci 7: 17. doi: 10.1186/1471-2202-7-17.

Zipursky SL, Wojtowicz WM, Hattori D. 2006. Got diversity? Wiring the fly brain with dscam. Trends Biochem Sci 31: 581-588. 


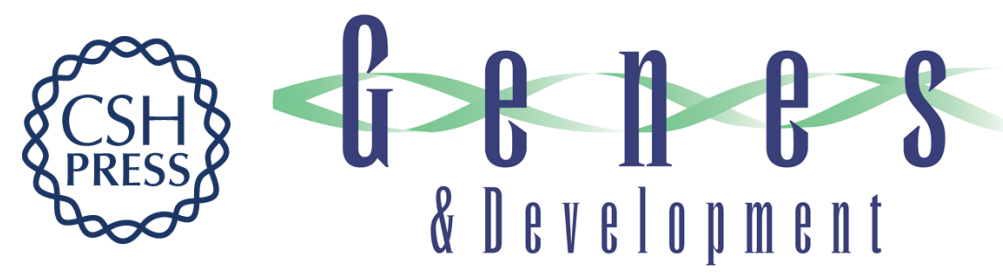

\title{
Understanding neuronal connectivity through the post-transcriptional toolkit
}

\author{
Carlos M. Loya, David Van Vactor and Tudor A. Fulga
}

Genes Dev. 2010, 24:

Access the most recent version at doi:10.1101/gad.1907710

$\begin{array}{ll}\text { References } & \text { This article cites } 111 \text { articles, } 32 \text { of which can be accessed free at: } \\ \text { http://genesdev.cshlp.org/content/24/7/625.full.html\#ref-list-1 }\end{array}$

License

Email Alerting Receive free email alerts when new articles cite this article - sign up in the box at the top Service right corner of the article or click here.

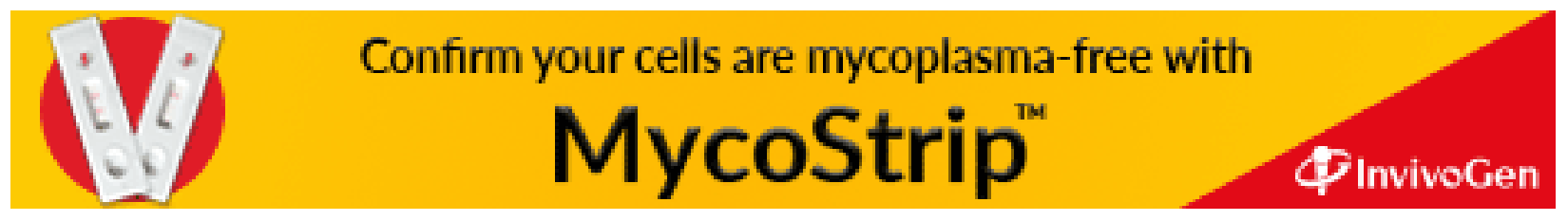

